\title{
SALAS BARBADILLO Y LA PARODIA CORTESANA DE LA «VIDA DEL MALVADO VARÓN A QUIEN EL VULGO DIO EL NOMBRE POSTIZO DE PANZA DICHOSA" \\ SALAS BARBADILLO AND THE COURTLY PARODY OF THE «VIDA DEL MALVADO VARÓN A QUIEN EL VULGO DIO EL NOMBRE POSTIZO DE PANZA DICHOSA»
}

\author{
LEONARDO Coppola \\ Università degli Studi «G. d'Annunzio» di Chieti-Pescara
}

\section{RESUMEN}

A través del análisis de la primera narración del «malvado varón» de El curioso y sabio Alejandro, juez y fiscal de vidas ajenas, de Alonso Jerónimo de Salas Barbadillo, se intentará desvelar la sátira política que se esconde detrás del primer retrato que avanza la apariencia de una Corte farsante. La materia satírico-cortesana representada en la voracidad del glotón «Panza dichosa», marcado por su final desnutrición, representaría, asimismo, la imagen decaída de una Corte infernal en la que Salas parece dirigirse directamente al monarca.

PalABRAS ClavE: Salas Barbadillo, novela, sátira, Quevedo, Corte.

\section{ABSTRACT}

Through the analysis of the first narration of the «malvado varón» in El curioso y sabio Alejandro, juez y fiscal de vidas ajenas, by Alonso Jerónimo de Salas Barbadillo, an attempt will be made to reveal the political satire that hides behind the first portrait that advances the appearance of a deceptive Court. The satirical-courteous matter represented in the voracity of the gluttonous «Panza dichosa», marked by its final malnutrition, would also represent the decayed image of a hellish Court in which Salas seems to address the monarch directly.

KeY WoRDS: Salas Barbadillo, novel, satire, Quevedo, Court.

\section{La figura cortesana DE «PANZA Dichosa»}

Desde principios del siglo XVII, Madrid se convirtió en el marco ideal de la ambigüedad y de la hipocresía, lo que permitió el nacimiento de un nuevo género

\footnotetext{
* Recibido: 16-03-2020. Aceptado: 25-07-2020.
} 
literario que daría pie a la reflexión y, aunque disimuladamente, al cambio de los aparentes hábitos peligrosos de sus habitantes. Autores como Antonio Liñán y Verdugo, con su Guía y avisos de forasteros que vienen a la Corte (1620), Fernández de Ribera, con Los antojos de mejor vista (1623), o Salas Barbadillo, concretamente con El curioso y sabio Alejandro, juez y fiscal de vidas ajenas (1634), serán los precursores del costumbrismo madrileño de Francisco Santos y Juan de Zabaleta. ${ }^{1}$ Salas Barbadillo, al igual que estos escritores, cultiva con interés satírico la imaginería de la cultura material urbana que le rodea. Sus textos se caracterizan por una vena costumbrista que manifiesta la vida cotidiana del Madrid de la época, su nobleza aparente y sus placeres mundanos. Estos se traducen en los excesos de comida, bebida, vestimenta y decoraciones domésticas, exhibidos tanto en los cuadros colgados en la galería del caballero Alejandro como en las «seis novelas cortas de carácter ejemplar» ${ }^{2}$ que, describiendo las pinturas del anfitrión de la casa-museo, manifiestan los goces frívolos de esas vidas que dan cuenta de la constante cotidianidad inculta de la urbe madrileña. ${ }^{3}$ Ahora bien, la perversa figura de «Panza dichosa», la primera narración que el madrileño nos presenta entre los tantos tipos estrambóticos de su librito, inaugura el paseo del autor por la tétrica galería de Alejandro, que, como intentaremos averiguar, inicia una parodia cortesana.

En este punto, debemos retomar la idea que ya fue señalada en otro lugar:4 aquella gran carcajada del visitante de nuestra galería motivada por la visión amorfa de la primera pintura, la de «Panza dichosa», y su relación con su antecedente en el Sueño del Juycio y de la Muerte de Quevedo. Aplicando la conjetura de lo cómico de Aristóteles, que se funda en lo feo y lo amorfo, y que sigue también en la teoría del «cómico de carácter» de Bergson, ${ }^{5}$ que relaciona la risa con una deformación de

\footnotetext{
${ }^{1}$ Cabe señalar que este autor bebe en su Día de fiesta por la mañana y por la tarde en Madrid (1654) de una burla parecida al glotón «Panza dichosa» de nuestro texto (GARcía SANTo-Tomás, E., Modernidad bajo sospecha. Salas Barbadillo y la cultura material del siglo XVII, Madrid, CSIC, 2008, p. 125 n. 6).

${ }^{2}$ Rey HazAs, A., Picaresca femenina (La hija de Celestina. La niña de los embustes, Teresa de Manzanares), Barcelona, Plaza y Janés, 1986, p. 37.

${ }^{3}$ Alvar Ezquerra, A., El nacimiento de una capital europea: Madrid entre 1561 y 1606, Madrid, Turner, 1989. Sobre el espacio urbano madrileño en la obra de Salas Barbadillo, García SANTo-Tomás, E., Modernidad bajo sospecha..., ob. cit., GARcía SAnTo-Tomás, E., Espacio urbano y creación literaria en el Madrid de Felipe $I V$, Madrid, Universidad de Navarra-Iberoamericana-Vervuert, 2004, ClYMER, C., The representation of culture in Golden Age Madrid: between attraction and repugnance, Nottingham, University of Nottingham, 2014 y Piqueras Flores, M., Alonso Jerónimo de Salas Barbadillo y la conformación de las colecciones de metaficciones en el Madrid cortesano, Tesis doctoral defendida en la Universidad Autónoma de Madrid, Facultad de Filosofía y Letras, Departamento de Filología Española, 2016, pp. 33-46.

${ }^{4}$ Coppola, L., «Salas Barbadillo y el quehacer grotesco: "Las líneas de este pincel y los renglones de esta pluma" en El curioso y sabio Alejandro, juez y fiscal de vidas ajenas (1634)"», en M. ALBERT, V. ARANDA ARRIBAS, L. Coppola (eds.), La narrativa de Alonso Jerónimo de Salas Barbadillo, Berlín, Peter Lang (Bonner Romanistische Arbeiten, 121), 2020, pp. 203-223.
}

${ }^{5}$ Bergson, H., La risa, Barcelona, Plaza y Janés, 1956, p. 839. 
la naturaleza, ${ }^{6}$ Salas Barbadillo concreta la comicidad como principio de un defecto estético o comportamental del personaje que la encarna. Sin embargo, como reconoce Maestro ${ }^{7}$ a propósito de su teoría de lo cómico de Cervantes, este tipo de risa se enlazaría con la crítica. Pues bien, a través de un espectáculo cumplidamente deformado, Salas, a la manera cervantina, hace que «la risa precede a la crítica y la estimula contra la intolerancia». ${ }^{8}$ En el contexto social del madrileño, el objetivo de la risa provocada por la deformación manifiesta sería, por lo tanto, «desmitificar los imperativos categóricos de la moral y de la ideología dominante». ${ }^{9}$ Este hecho nos lleva a la teoría de lo cómico de Close, según el cual «la risa provocada por el comportamiento del personaje ridículo suele implicar un juicio moral y una adjudicación social de grados de mérito» ${ }^{10}$. La inicial carcajada del visitante de la galería nos mueve, por lo tanto, de la pintura ridícula al mensaje verbal del epítome que «embaraza nuestra narración»; 11 esto es, la risa se convierte en algo serio. Se manifiesta, así, la teoría freudiana ${ }^{12}$ en la que lo cómico se convierte en el medio con el cual las personas se burlan de los tabúes generales que se asocian a la vergüenza social, liberando impulsos agresivos o reprimidos. ${ }^{13} \mathrm{El}$ componente cómico se propone, así pues, «más para la compasión que para la risa». ${ }^{14}$ Ahora bien, la narración trata de un «bárbaro idólatra de su vientre», ${ }^{15}$ un "glotón y estafador» que vive en Madrid, «madre de monstruos y de prodigios», ${ }^{16}$ expresión que confirma la típica paradoja barroca señalada por Alvar Ezquerra: «Dentro de Madrid hay dos ciudades: la cortesana y la menesterosa». ${ }^{17}$

\footnotetext{
${ }^{6}$ HeRnÁNDEZ GonZÁLEZ, M.․․ B., «El humor, la ironía y el cómico: códigos transgresores de lenguajes e ideologías», Signa: revista de la Asociación Española de Semiótica, 8 (1999), p. 219.

${ }^{7}$ MAestro, J. G., «Cervantes y el entremés, poética de una comicidad crítica», en F. B. Pedraza Jiménez y R. González Cañal, Con los pies en la tierra. Don Quijote en su marco geográfico e histórico, 2 vols., I, Cuenca, Universidad de Castilla / La Mancha, 2008, pp. 525-536.
}

${ }^{8}$ Maestro, J. G., «Cervantes y el entremés...», ob. cit., p. 528.

${ }^{9}$ BRavo, M. D., «Los entremeses cervantinos, valores sociales y risa crítica: El retablo de las maravillas», en L. Von der Walde y S. González García (eds.), Dramaturgía española y novohispana (siglos XVI y XVII), Itzapalapa, México, Universidad Autónoma Metropolitana, 1993, p. 40.

${ }^{10}$ Close, J. A., Cervantes y la mentalidad cómica de su tiempo, Alcalá de Henares, Biblioteca de Estudios Cervantinos, 2007, p. 17.

${ }^{11}$ Salas Barbadillo, A. J., «El curioso y sabio Alejandro, fiscal y juez de vidas ajenas», en E. de Ochoa (ed.), Tesoro de novelistas españoles antiguos y modernos, t. II, París, Fain y Thunot, 1847, p. 3

${ }^{12}$ Freud escribe: «No hay ninguna duda de que la esencia del humor consiste en ahorrarse los afectos que habría dado ocasión la situación y en saltarse mediante una broma la posibilidad de exteriorizaciones de sentimiento» (Freud, S., «El humor», en Obras Completas, Vol. XXI, Buenos Aires, Amorrortu, 1991, p. 158.

${ }^{13}$ Close, J. A., Cervantes y la mentalidad..., ob. cit., p. 226.

${ }^{14}$ SAlas Barbadillo, A. J., «El curioso y sabio...», ob. cit., p. 7.

${ }^{15}$ Salas Barbadillo, A. J., «El curioso y sabio...», ob. cit., p. 3.

${ }^{16}$ Salas Barbadillo, A. J., «El curioso y sabio...», ob. cit., p. 3.

${ }^{17}$ Alvar Ezquerra, A., El nacimiento de..., ob. cit., p. 151. 


\section{Leonardo Coppola}

Salas hace notar que «aquel reino ventoso, vocinglero y cristalino» ${ }^{18}$ estaba habitado por este «archiglotón de España y [...] langosta racional y discursiva», ${ }^{19}$ cuya voraz gula incluso llegó a comerse todas las riquezas de sus antepasados «en menos de 7 lústros», ${ }^{20}$ y del que no hubo manera de deshacerse. El madrileño recurre a la bíblica imagen destructora de la langosta que entraba «en la tierra para arruinarla». ${ }^{21}$ Remitiendo a la fuente de las Sagradas Escrituras, según las cuales la langosta representa la octava calamidad sobrenatural que Dios inflige a los egipcios, ${ }^{22}$ tanto para Salas como para Quevedo ${ }^{23}$ es sinónimo de pestilencia y «de plaga mortífera» ${ }^{24}$ «con que castiga Dios los pecados de los hombres, y regularmente dura siete años» (véase $A u t$.$) , como los «7 lústros» de Salas. Estas llegan inesperadamente gracias a$ la ventaja que les proporciona un viento favorable, al igual que el malvado varón, producto y condición propicia de «aquel reino ventoso» ${ }^{25}$ que, por su voracidad, como la bíblica langosta epidémica, convierte en un desierto desolado la abundancia de una tierra fértil, ${ }^{26}$ haciendo que «los años más fecundos y pródigos pareciesen estériles y mezquinos». ${ }^{27}$

En efecto, este personaje «peregrinó todos los pueblos de España» («Pinto», «Zamarramala», «Alcalá», «Portugal», «Zaragoza»), siendo comedor «tan infatigable y perseverante [...] de quesos de Alentejo y Tronchón» ${ }^{28}$ y bebedor no menos moderado de vinos de Castilla, Portugal y Aragón. El viaje entre viandas y bebidas, incluso traídas de fuera, representa un ataque a los excesos del vicio capital de la gula, «madre fecundísima de la mayor parte de los demás». ${ }^{29}$ Es más, «con la embriaguez engendra a la soberbia y a la ira, [... ] lujuria, y a la soñolienta pereza». ${ }^{30} \mathrm{El}$ autor critica el perturbado gasto en alimentación por parte de los ricos que ya desde principios del Renacimiento,

\footnotetext{
${ }^{18}$ Salas Barbadillo, A. J., «El curioso y sabio...», ob. cit., p. 4.

${ }^{19}$ Salas Barbadillo, A. J., «El curioso y sabio...», ob. cit., p. 3.

${ }^{20}$ Salas Barbadillo, A. J., «El curioso y sabio...», ob. cit., p. 5.

${ }^{21}$ Jue 6:5.

${ }^{22}$ Éx 10:1-20.

${ }^{23}$ «Ay plaga de letrados» (M653) a la que le sigue la consideración del Marqués de Villena: «Valiera más a España la langosta perpetua que liçençiados al quitar» (M660) (Quevedo, F., Sueños y discursos, 2 vols., J. 0. Crosby (ed.), Madrid, Castalia, 1993, pp. 1453-1454).

${ }^{24}$ Éx 10:17.

${ }^{25}$ SAlas Barbadillo, A. J., «El curioso y sabio...», ob. cit., p. 4.

${ }^{26}$ Joe $2: 3$.

${ }^{27}$ Salas Barbadillo, A. J., «El curioso y sabio...», ob. cit., p. 3.

${ }^{28}$ Salas Barbadillo, A. J., «El curioso y sabio...», ob. cit., p. 4.

${ }^{29}$ Salas Barbadillo, A. J., «El curioso y sabio...», ob. cit., p. 7.

${ }^{30}$ Salas Barbadillo, A. J., «El curioso y sabio...», ob. cit., p. 7.
} 
según estudia Maravall, ${ }^{31}$ había sido tratado en autores como Villalón, en El Crotalón; Mexía, en su Diálogo sobre la ociosidad, y Torquemada, en sus Diálogos. El ataque a los ricos con aire de poderosos y a los nobles vuelve también en El Prado de Madrid y el baile de la capona, tercera de las Cuatro comedias antiguas que el vulgo llama entremeses que componen el «Plato quinto» de las Coronas del Parnaso y platos de las Musas, donde el músico Robledo dice: «siempre son los más ricos los más bestias». ${ }^{32}$ Según esta visión del madrileño, en Castilla los nuevos ricos manifestaban exteriormente su distinción hegemónica no solo en vestimentas y otros consumos suntuarios como viviendas o coches, sino también con la comida más variada, abundante y preciada. ${ }^{33}$

Sea como fuere, «Panza dichosa», comparado con la langosta bíblica antes, y luego, como veremos a continuación, con Saturno, se convierte en árbol por la excesiva fruta que ingiere: «le podían haber nacido en el vientre los árboles guindos, cerezo, albaricoques y durazno, porque más parecía que sembraba en él frugales que no comía frutas». ${ }^{34}$ En nuestra opinión, Salas vuelve otra vez a la imagen de la plaga de la langosta: «Llevarás mucha semilla al campo, pero poco recogerás, porque la langosta la devorará». ${ }^{35}$ A continuación, el madrileño exhibe un nacimiento forzoso. Engendrar algo con esfuerzo, con la violencia corporal, crea una cara oscura de los placeres cortesanos que se presentan como situaciones perversas, delirantes, frustradas o de pura transacción económica. ${ }^{36}$ Con la subida al poder de Felipe IV se afirmaron nuevas fuerzas políticas, administrativas y económicas que normalizaron una descomunal costumbre en el gasto de productos aparatosos en la indumentaria y, como se quiere demostrar concretamente aquí, en la comida. En suma, García Santo-Tomás ${ }^{37}$ considera que este personaje grotesco no solo representa un ataque a la voracidad de este nuevo mundillo, sino más bien una provocación a la Corte en sí. La urbe atraída por los placeres materiales no solo devora toda la vegetación - «Jehová ahora dijo a Moisés: "Extiende tu mano sobre la tierra de Egipto para las langostas, para que suban sobre la tierra de Egipto y se coman toda la vegetación de la tierra, todo lo que el granizo ha

\footnotetext{
${ }^{31}$ Maravall, J. A., La literatura picaresca desde la historia social, Madrid, Taurus, 1986, p. 564.

32 Salas Barbadillo, A. J., Coronas del Parnaso y platos de las Musas, Madrid, Imprenta del Reino, 1635, p. $143 r$.

33 Álvarez-Ossorio Alvariño, A., «Rango y apariencia. El decoro y la quiebra de la distinción en Castilla (ss. XVI-XVIII)», Revista de historia moderna, 5, 17 (1998-1999), p. 266.

${ }^{34}$ Salas Barbadillo, A. J., «El curioso y sabio...», ob. cit., p. 4. Se trata del episodio del que Juan de Zabaleta bebe en su Día de fiesta por la mañana y por la tarde en Madrid (1654) (GARcía SAnTo-Tomás, E., Modernidad bajo sospecha..., ob. cit., p. 125 n. 6).

${ }^{35}$ Deuteronomio 28:38.

${ }^{36}$ García Santo-Tomás, E., Modernidad bajo sospecha..., ob. cit., p. 126.

${ }^{37}$ García SAnto-Tomás, E., Modernidad bajo sospecha..., ob. cit., p. 125.
} 
dejado que quede" $»^{38}-$ sino también las demás sustancias (lino, seda o madera) de las que se nutre la langosta ${ }^{39}$ - debajo de la cual bien se esconden los palacios del poder - ; todo lo que, de hecho, los nuevos ricos imitaban de los poderosos en el consumo suntuario de trajes, viviendas y mobiliario.

La capital era pues el escenario más conveniente para un «glotonazo» ${ }^{40}$ al que el vulgo llamó «Panza dichosa» porque «solía meter a saco las más célebres y festejadas despensas de la corte». ${ }^{41}$ Como las langostas apocalípticas que "penetran precipitadamente en la ciudad. Sobre el muro corren. Por las casas suben. Por las ventanas entran como el ladrón», ${ }^{42}$ el voraz "siempre tuvo [...] muchas ventanas por donde asomarse, y aun su juicio andaba no pocas veces asomado». ${ }^{43} \mathrm{Al}$ igual que en el Caballero Puntual, Salas no hace sino «descubrir las brechas de la fortaleza noble algo amenazada por el tropel de advenedizos aventureros que pululan en Madrid». ${ }^{44} \mathrm{El}$ autor manifiesta la diabólica crueldad caníbal del coloso que llegó a comerse hasta a su «veneranda madre ${ }^{45}$ y que, al final de su biografía y con su mísera muerte, es a su vez comido en un calamitoso carnero por los gusanos de los sepulcros que se nutrirán de los mismos miserables de los que se alimentó el glotón en vida.

La asociación con Saturno se debe a su fama de devastador pernicioso que causa muertes y escarmientos. En palabras de Salas Barbadillo, aquel Saturno que, «provocado del miedo ambicioso de no perder el reino, se cebó tirano en la sangre inocente de los que engendraba». ${ }^{46} \mathrm{Al}$ igual que ese dios, «Panza dichosa» devora tanto a sus hijos como a sus antepasados — «veneranda madre» - , en la tónica de una «sátira de la usurpación doméstica del poder». ${ }^{47}$ En nombre del mantenimiento de ese dominio se va produciendo un harakiri ejemplificado aquí: «¿No sería loco furioso

\footnotetext{
${ }^{38}$ Éx 10:12.

${ }^{39}$ Buj BuJ, A., «La plaga de la langosta. Permanencia de un riesgo biológico milenario», Scripta Nova. Revista electrónica de Geografía y Ciencias Sociales, XII (2008), p. 270.

${ }^{40}$ Salas Barbadillo, A. J., «El curioso y sabio...», ob. cit., p. 6.

${ }^{41}$ Salas Barbadillo, A. J., «El curioso y sabio...», ob. cit., p. 3.

42 Joe 2:9.

${ }^{43}$ Salas Barbadillo, A. J., «El curioso y sabio...», ob. cit., p. 4.

${ }^{44}$ VITSE, M., «Salas Barbadillo y Góngora: burla e ideario de la Castilla de Felipe III», Criticón, 80 (1980), p. 20.

${ }^{45}$ Salas Barbadillo, A. J., «El curioso y sabio...», ob. cit., p. 3.

${ }^{46}$ Salas Barbadillo, A. J., «El curioso y sabio...», ob. cit., p. 3. Recordemos que Saturno obtuvo de su hermano mayor Titán el permiso de reinar en su lugar a condición de que no tuviese hijos. Sin embargo, a causa de los hijos que tuvo del matrimonio con Ops y para respetar el pacto con su hermano, decidió devorarlos.
}

${ }^{47}$ VITSE, M., «Salas Barbadillo y Góngora...», ob. cit., p. 121. 

aquel que dándole una espada para que con ella defendiese su vida, se arrojase de pechos sobre su punta, y la hiciese instrumento de su muerte?». ${ }^{48}$

Si bien para Vitse ${ }^{49}$ la intención no radica en satirizar los nobles sino en advertir la amenaza que suponen los arribistas, no se puede desautorizar, según reconoce López Martínez,,$^{50}$ una crítica contra el estamento dominante de la sociedad, el que abre paso a esos advenedizos. Notamos pues cómo Salas suministra a esa ridícula persona las conductas de los estratos altos de la sociedad que él creía ser los más nobles, pero que nada son sino los defectos de la «excesiva poltronería [...], la promiscuidad social; propensión a la tiranía». ${ }^{51}$ Justo en ese momento en el que la figura, que al principio suscita hilaridad por su naturaleza deforme, aplica literalmente esos vicios, según una visión idealista y para la realización de sus metas, «esa persona cesa de producir efecto cómico».52 En definitiva, Salas llega a la sátira por medio de la ridiculización desencadenada por el primer impacto visual.

La historia mitológica de Saturno estuvo de moda en las interpretaciones alegóricas barrocas y en la pintura. Se puede encontrar, entre las muchas manifestaciones, en el grabado Melanconia, de la serie «los cuatro temperamentos», de Harmen Jansz Muller, de 1566, o en el lienzo de Rubens, Saturno devorando a su hijo (1636), comisionado por Felipe IV para la Torre de la Parada, decorada, además, con las escenas de Metamorfosis de Ovidio. Precisamente, el antiguo autor romano ya había atribuido la crueldad a la figura saturniana que, tiempo después, Salas recuperaría para su «malvado varón». Es más, este coloso

no perdonó a las entrañas de madre tan generosa, y aun repitió la culpa como el ave infernal de Ticio, pues tantas veces se las royó, cuantas le volvieron a renacer, dejando sus plazas, que amanecían abundantísimas y copiosas (con solo dar una vuelta por ellas), desiertas y mendigas..$^{53}$

Tanto en las Metamorfosis de Ovidio (IV, 447-464) como en la Eneida de Virgilio (VI,595-600) se narra el castigo infligido al gigante Ticio por haber violado a Leto, madre de Zeus, y cuyo hígado, que se regeneraba, fue devorado en el Hades por un buitre. El «ave infernal de Ticio» ${ }^{54}$ vuelve a una visión nefasta. Como en el caso de Saturno

\footnotetext{
${ }^{48}$ Salas Barbadillo, A. J., «El curioso y sabio...», ob. cit., p. 6.

${ }^{49}$ VITSE, M., «Salas Barbadillo y Góngora...», ob. cit., p. 20.

${ }^{50}$ Salas Barbadillo, A. J., El caballero puntual, E. López Martínez (ed.), Madrid, Real Academia Española/ Centro para la Edición de Clásicos Españoles, 2016, p. 158.

${ }^{51}$ VITSE, M., «Salas Barbadillo y Góngora...», ob. cit., p. 119.

52 Freud, S., «El chiste y su relación con lo inconsciente», en Obras Completas, Vol. VIII, Buenos Aires, Amorrortu, 1995, p. 219.

53 Salas Barbadillo, A. J., «El curioso y sabio...», ob. cit., p. 3.

${ }^{54}$ Salas Barbadillo, A. J., «El curioso y sabio...», ob. cit., p. 3.
} 
devorando a sus hijos, Salas acude otra vez a una historia mitológica muy en auge en las artes visuales. Nos referimos, claro es, al óleo sobre lienzo que Tiziano realizó en 1565 por encargo de María de Hungría (1505-1558) tras la batalla de Mühlberg y que pertenece a una de las llamadas Furias o Condenados, colección de las cuatro figuras (Ticio, Tántalo, Sísifo e Ixión) castigadas en el Hades como muestra de la victoria de las Virtudes sobre los Vicios ubicadas en el Alcázar de Madrid hasta el incendio de 1734. Con las Furias María quiso mostrar en clave mitológica el destino reservado a quienes se rebelaban contra el poder legítimo. El cuadro fue concebido entonces con una clara finalidad política como advertencia para quienes osasen desafiar el poder imperial. ${ }^{55}$

Así y todo, tras la plaga adelantada con la apestosa langosta bíblica, Salas parece rescatar el enclave alegórico-político de las dos imágenes mitológicas traídas. Las asociaciones atribuidas al primer varón descrito nutren la función del cuerpo grotesco, como reconoce García Santo-Tomás, ${ }^{56}$ que favorece la presencia invariable de lo gigantesco. El «gigantismo», según refiere Américo Castro, ${ }^{57}$ ya encubría una crítica socio-política bien presente en El Quijote. Tal monstruosidad se formaba de clérigos, gobernantes y ricos, que, para el estudioso, representa un ataque contra la vida religiosointelectual que sometía a los españoles de su época. En una aplicación de la idea del maestro cervantista sobre nuestro texto, en Salas notamos la misma invectiva contra el sistema político y social de sus tiempos. Los gigantes se presentan como enemigos de los hombres, «simbolizan siempre la soberbia de lo que sale de los límites de lo humano, y por ello mismo, fuerzas antihumanas que se deben eliminar de la faz de la tierra». ${ }^{58}$ La perversidad de esos colosos vanidosos es, al igual que en El Quijote, una dimensión «estrictamente moral». ${ }^{59}$ Retomando lo dicho por Alvar Ezquerra, ${ }^{60}$ según el cual «dentro de Madrid hay dos ciudades: la cortesana y la menesterosa», en aquel Madrid convivían los gigantes padres por un lado y los descendientes por el otro. De nuevo, viene a bosquejarse esa «usurpación domestica del poder» ${ }^{61}$ que se refleja en la

\footnotetext{
${ }^{55}$ La interpretación alegórica se deja entrever también en otras obras del pintor veneciano y en común relación con un autor que también sirvió de modelo a Salas Barbadillo. Nos referimos, claro está, al Emblemata líber (1531), de Andrés Alciato, modelo que pudo servir a Salas para la combinación de las pinturas colgadas en la galería de Alejandro con los comentarios expositivos, y cuyos motivos, según los estudios de ZAFrA, R., «El prudente Tiziano y su emblema de la prudencia», Potestas. Revista del Grupo Europeo de Investigación Histórica, 3 (2010), parecen suministrar materia al arte de Tiziano. Es el caso, por ejemplo, de las tres cabezas humanas del cuadro Alegoría de la Prudencia, que bebe de los emblemas de Alciato.

${ }^{56}$ García SAnto-Tomás, E., Modernidad bajo sospecha..., ob. cit., p. 125.

${ }^{57}$ CASTRo, A., «Como veo ahora el Quijote», estudio introductorio a la edición de El ingenioso don Quijote de la Mancha, Madrid, Magisterio Español, 1971, p. 20.

${ }^{58}$ Durán Guerra, L., «Don Quijote como universal fantástico», Anales Cervantinos, 50 (2018), p. 93.

${ }^{59}$ DurÁN GUERRA, L., «Don Quijote como...», ob. cit., p. 92.

${ }^{60}$ Alvar Ezquerra, A., El nacimiento de..., ob. cit., p. 151.

${ }^{61}$ VITSE, M., «Salas Barbadillo y Góngora...», ob. cit., p. 119.
} 
transición hacia lo nuevo o, si queremos, en la imitación que los plebeyos hacen de los gigantes, evidentemente identificados con los nobles y los clérigos. En otros términos, la Corte es el gigante que se lo come todo en nombre del mantenimiento del poder absoluto. Sin embargo, el «vulgo rudo y soberbio», ${ }^{62}$ que también se convertirá en lo nuevo y que llamó «Panza dichosa» a la Corte - aunque hubieran sido más propios los adjetivos «malvada o infernal», como deja claro el narrador -, inicia a imitarla, reduciéndola, a su vez, a miseria y obligándolo a mendigar. ${ }^{63} \mathrm{El}$ «malvado varón», que - según deja constancia en el texto el autor - un tiempo competía con el frenesís de Heliogábalo (emperador conocido por su gula), murió en el hospital y fue sepultado en un «carnero, que en aquel de quien él comió tanto en vida, fue comido después de muerto». ${ }^{64}$ La muerte del gigante engendrado por la ostentosa política glotona de la corte está provocada por la soberbia del pueblo imitador, por su deseo de lanzarse más allá de sus posibilidades, pretendiendo igualarse con la nobleza. Como reconoce Durán Guerra, ${ }^{65}$ la soberbia del hombre, que quiere ser más de lo que es, le hace aspirar «al gigantismo olvidando lo que le hace solamente humano», lo que le pasó a Don Quijote, cuya «vanidad de la fama y la gloria de este mundo» produjeron una «contradicción insoluble entre el sueño de inmortalidad de la Humanidad y la realidad del fin de todas las cosas que se impone». ${ }^{66}$

Así las cosas y en línea con la cultura visual barroca, los tres estratos de la sociedad estamental (Nobleza, Clerecía y Plebe) deberían presentarse como una realidad cotidiana visible y evidente, ${ }^{67}$ lo que Salas hace en su texto ya desde la primera narración. «Panza dichosa» inaugura, así pues, el desfile de los viciosos de la sociedad barroca española, «los dados a vanidad y gula» (J28), ${ }^{68}$ como en Los Sueños del Juycio de Quevedo, y al mismo tiempo la consiguiente trágica muerte que caerá sobre cada uno de los monomaniáticos de la galería. El adverso destino de la vida viciosa de cada uno es, según creemos, la culminación de la materialidad y de las vanidades. El retrato sirve, de tal manera, de elemento memorial: la muerte física nos libra del materialismo al quedarnos solo el alma, que es lo que la pintura intenta dejarnos en herencia. Los personajes mueren en las breves narraciones, pero nos quedamos con la esencia moral, con el alma mostrada por los retratos que albergan la ficción de galería de Alejandro. El cuadro se convierte así en un cuerpo vivo. Como con la aparición de la Muerte en

\footnotetext{
${ }^{62}$ Salas Barbadillo, A. J., «El curioso y sabio...», ob. cit., p. 5.

${ }^{63}$ Salas Barbadillo, A. J., «El curioso y sabio...», ob. cit., p. 5.

${ }^{64}$ Salas Barbadillo, A. J., «El curioso y sabio...», ob. cit., p. 5.

${ }^{65}$ DurÁn Guerra, L., «Don Quijote como...», ob. cit., p. 100.

${ }^{66}$ DurÁn Guerra, L., «Don Quijote como...», ob. cit., p. 100.

${ }^{67}$ Álvarez-Ossorio Alvariño, A., «Rango y apariencia...», ob. cit., p. 266.

${ }^{68}$ Quevedo, F., Sueños y discursos, ob. cit., I, p. 132.
} 
Quevedo, estas imágenes representan la igualdad de todas las clases delante de su aparición: «soys bosotros mismos buestra muerte: [...] todos soys muertes de cada uno de bosotros mismos» (M260-262). ${ }^{69}$

Las mesmas cosas en que más nos olvidamos de la muerte, son en las que más debiéramos acordarnos de ella. Come un hombre, y si le preguntáis el porqué, dice que por no morir. Y responde mal, que no come sino por entretener el vivir, pues aunque coma no dejará de morir al tiempo que le está su fin decretado; y es tan ciego, que olvidado del origen donde tuvo principio este comer, que fue en el propio morir, [...] come [...] con bárbaro desorden aquello que le anticipa el morir, saliendo él propio a ofrecerse al camino a la misma muerte, de quien tiene por infalible que va huyendo. ${ }^{70}$

Esta declaración de Salas está en diálogo con los versos I610-627, de Quevedo, dedicados a los hombres que sucumben a la imprevista llegada de la langosta ${ }^{71}$ y detrás de los cuales se halla la presencia constante de la muerte en nuestras vidas: «vivir es morir viviendo» $(\mathrm{M} 264) .{ }^{72}$

Con sano criterio, si bien el coloso se devoró «más de un millón de hombres» ${ }^{73}$ - que sería aproximadamente la población cortesana de aquella época - por gula y no por necesidad («vivió para comer, no comió para vivir» ${ }^{74}$ ), se convierte él mismo en alimento para los gusanos que, pese a todo, solo podrán comer lo que queda de un hombre «tan consumido» que se había alimentado hasta de los gusanos del propio sepulcro - «reparó su vida con la misma muerte» ${ }^{75}-$. No cabe duda de que en el sepulcro el voraz iba a encontrarse con los gusanos que ya no eran los hombres viles y abatidos (véase Aut. «gusano») del que se cebó el glotón en vida, sino los que se sustentarán de su carne: «los gusanos solos de los sepulcros, estos son los verdaderos caribes, pues no saben mantenerse sino de carne humana» ${ }^{76} \mathrm{y}$ tierra. A esto, como sigue el autor, «yo replicaré que en tierra y carne humana, no diferencian el manjar, sino el nombre, porque tierra y carne humana son una misma cosa». ${ }^{77}$ Según constata Maravall, ${ }^{78}$ las palabras acentúan la fuerza adversa de la muerte que de la misma manera aparecía también en Quevedo: «conmigo llevo la tierra y la muerte». ${ }^{79}$ La presencia

\footnotetext{
${ }^{69}$ Quevedo, F., Sueños y discursos, ob. cit., I, p. 223.

${ }^{70}$ Salas Barbadillo, A. J., «El curioso y sabio...», ob. cit., p. 6.

${ }^{71}$ Joe $1: 4 ; 2: 5,25$.

${ }^{72}$ Quevedo, F., Sueños y discursos, ob. cit., I, p. 1213.

${ }^{73}$ Salas Barbadillo, A. J., «El curioso y sabio...», ob. cit., p. 5.

${ }^{74}$ Salas Barbadillo, A. J., «El curioso y sabio...», ob. cit., p. 3.

${ }^{75}$ Salas Barbadillo, A. J., «El curioso y sabio...», ob. cit., p. 5.

${ }^{76}$ Salas Barbadillo, A. J., «El curioso y sabio...», ob. cit., p. 6

${ }^{77}$ Salas Barbadillo, A. J., «El curioso y sabio...», ob. cit., p. 6.

${ }^{78}$ MaravalL, J. A., La cultura del Barroco, Barcelona, Planeta, 2012, p. 269.

${ }^{79}$ De los remedios de cualquier fortuna, en Obras: Prosa, p. 887 apud MARAVALL, J. A., La cultura..., ob. cit., p. 
constante de la muerte hace que su visión cruel alimente una perturbación que se refleja tanto en las narraciones breves como en los cuadros colgados con «desproporciones y contradicciones que se observan en su imagen» (M231-239) ${ }^{80}$ y que en varios casos despiertan lo disparatado y lo cómico, como ya se ha delineado al principio con la carcajada provocada por la deformidad que algunos detalles de los retratos causan en el observador y que, en realidad, están en contradicción con la verdadera figura que detrás de ellos se esconde: «No son todos los venenos los que nos preparan nuestros enemigos, mas son los que nosotros nos tomamos por nuestra elección, cubiertos con el oro mentido de aquel sensual deleite». ${ }^{81}$ Dicho de otra forma, no todo aparece según es, hecho que debería llevarnos a desconfiar de todos los que cultivan las apariencias. De la misma manera, las copiosas y ostentativas mesas, mientras más lo son de manjares peregrinos y preciosos, mas lo son de achaques, de dolores, de sueño, de pereza, y el abrirle más puertas a la muerte con este artificio goloso de las que ella naturalmente se sabe ${ }^{82}$.

\section{LA FACETA INFERnAl DE UNA CORTE FARSANTE}

Sin embargo, aunque el «varón pulido y limpión» de la segunda biografía fue templado en el comer - como aconsejaba el autor en la conclusiva reparación moral a la voracidad de la primera biografía - con «palillos y tenedores, a imitación de lo que nos refieren algunas historias modernas de ciertos gentiles, grandes políticos y no menos ilustres filósofos morales», ${ }^{83}$ «tuviera su fin en la misma parte que Panza dichosa ${ }^{84}$ si no se hubiera muerto temprano por otra manía que encarna: los excesos en materia de aseo y moda. ${ }^{85}$ Desplazándonos solo por un momento hacia el esquema estructural de nuestras narraciones breves, Salas, con estos dos recursos que remiten a la vida del «malvado varón» anteriormente presentada, crea una continuación narrativa entre los cuentos que supone una secuencia fija establecida por el autor. ${ }^{86}$

\section{9.}

${ }^{80}$ Quevedo, F., Sueños y discursos, ob. cit., I, p. 16.

${ }^{81}$ Salas Barbadillo, A. J., «El curioso y sabio...», ob. cit., p. 6.

${ }^{82}$ Salas Barbadillo, A. J., «El curioso y sabio...», ob. cit., p. 6.

${ }^{83}$ Salas Barbadillo, A. J., «El curioso y sabio...», ob. cit., p. 10. El autor se refiere claramente a El Cortesano, de Castiglione.

${ }^{84}$ SALAS BARBADILlo, A. J., «El curioso y sabio...», ob. cit., pp. 10-11.

${ }^{85}$ Sobre este asunto remitimos en particular a CHEvalier, M., «Cuestiones de aseo Luis Zapata, Lucas García Dantisco, Alonso Quijano», Incipit, 11 (1991), pp. 153-160, GonZÁLEZ CAÑAL, R., «El lujo y la ociosidad durante la privanza de Olivares: Bartolomé Jiménez Patón y la polémica sobre el guardainfante y las guedejas», Criticón, 53 (1991), pp. 71-96, y García SANTo-Tomás, E., Modernidad bajo sospecha..., ob. cit., pp. 145-153.

${ }^{86}$ También se ha analizado la importancia de la función óptica de todos los episodios descritos como hilo conductor que favorece el avance de una historia a otra en la galería-marco de Alejandro en CoppolA, L., «La galería artística como proyecto marco de El curioso y sabio Alejandro, fiscal y juez de vidas ajenas (1634): 
Por cierto, y ya de vuelta a nuestro asunto de interés, las dos acaban con la muerte súbita y cruel del protagonista. A este propósito, el «varón ridículo», ignorando «cuan cerca estaban su carne y sus huesos de la misma hediondez y podredumbre», ${ }^{87}$ quiso ser embalsamado para no ir al muladar. Se presenta, así pues, la imagen quevedesca del sepulcro hermoso por fuera pero podrido por dentro (A64-65) que «consta la idea de contraste entre el exterior y el interior de un hipócrita». ${ }^{88}$ Según Salas Barbadillo, los aromas y las vanidades con los que se consideraba incorruptible no son nada sino falsedades y «especias aromáticas con que les sazonan la carne a los gusanos: para que la coman [...] poltronamente [...], buscándola unos hombres para otros hombres, la codicia de los unos para la gula de los otros». ${ }^{89}$

La crítica a estos maniáticos de la moda - que «casi desnudos creemos estar bien vestidos» ${ }^{90}-\mathrm{y}$ de los afeites - pero cuyos «más preciosos aromas no pueden cerrar la puerta a la corrupción, sino entretenerla» ${ }^{91}$ - fue otra práctica común que llevó, según muchos escritores, al declive del dominio español, de su economía nacional y de la austeridad del hombre convertido en «lindo» por el excesivo esmero con el que cuidaba su aspecto exterior. ${ }^{92}$ Salas, como esos escritores, sostiene que, acudiendo a una ostentación de vestiduras excesivamente extravagantes y ridículas, "paramos en el mayor extremo de la desnudez, que es la muerte; pues para llevarnos a la sepultura, nos desnudan casi en carnes, donde pasando más adelante esta desnudez, los gusanos nos desnudan de ella, y nos dejan en los huesos»,93 imagen que, según constata Maravall, ${ }^{94}$ revela «los peligros del mundo social y político». Se actualiza así el anterior castigo de Ticio atormentado del buitre que le come el hígado como imagen

Salas Barbadillo en el Palacio del Rey Felipe IV», JANUS: estudios sobre el Siglo de Oro, 9 (2020), pp. 191-220." 191-220.

${ }^{87}$ Salas Barbadillo, A. J., «El curioso y sabio...», ob. cit., p. 11.

${ }^{88}$ Quevedo, F., Sueños y discursos, ob. cit., I, p. 1054.

${ }^{89}$ Salas Barbadillo, A. J., «El curioso y sabio...», ob. cit., p. 11.

${ }^{90}$ Salas Barbadillo, A. J., «El curioso y sabio...», ob. cit., p. 12.

${ }^{91}$ Salas Barbadillo, A. J., «El curioso y sabio...», ob. cit., p. 11.

${ }^{92}$ GonzÁlez CAÑAL, R., «El lujo y la ociosidad...», ob. cit., p. 93. Sobre el afeminamiento del hombre como crítica a la perdida de la masculinidad, MARTínEz-GóngorA, M., El hombre atemperado: Autocontrol, disciplina y masculinidad en textos españoles de la temprana modernidad, Nueva York, Peter Lang, 2005, p. 7: «la visión de los varones de la clase dominante como "afeminados" por parte de los miembros de la élite intelectual, se relaciona con la percepción de crisis en las formas de masculinidad hegemónicas, que se asocia al empobrecimiento económico de la nación y la falta de función de la nobleza en el incipiente orden mercantil, en cuyo desarrollo tan interesado se halla el nuevo sector burgués».

${ }^{93}$ Salas Barbadillo, A. J., «El curioso y sabio...», ob. cit., p. 12.

${ }^{94}$ Maravall, J. A., La cultura del..., ob. cit., p. 270. 
quevedesca del hombre que sufre la pena del infierno viéndose consumido por el Gusano de la Conciencia (I725-726). ${ }^{95}$

La realidad cortesana aparente no era tan perfecta como querían que se mostrase, lo que llevó Salas a ofrecer una "tienda portátil" [...] de estos nuevos fetiches barrocos» ${ }^{96}$ que habitaban «la infernal Babilonia» ${ }^{97}$ en la que el Madrid de la época se había convertido. Al igual que Quevedo, Salas quiere precisamente mostrar la hipocresía, el afeite, la fachada que tapa la superficie artificial y atractiva de Madrid, «admirable cuanto confusa Babilonia». ${ }^{98}$ Concretamente en El curioso y sabio Alejandro busca manifestar ese mundo interior carcomido, lo mismo que se esconde debajo de los «sepulcros hermossos: por de fuera blanqueados y llenos de molduras, y por dentro pudriçión y gusanos» (A64), ${ }^{99}$ esto es, «la misma hediondez y podredumbre» ${ }^{100}$ que se celaría debajo del aromatizado «Majadero pulido».

El descubrimiento de ese mundo interior podrido concretamente en una casamuseo que manifestaba las condiciones de ostentosidad de un coleccionismo de un personaje extravagante hace que tanto el «narrador» quevedesco como el salasiano se encaminen en una galería que, en nuestro caso, tiene todos los rasgos de un mundo infernal. Profundizando en lo ya señalado, Quevedo llegó «a una galería donde estava Luzifer [...] no entré dentro porque no me atreví a poder sufrir su aspecto disforme» (I1192-1195) ${ }^{101}$ durante su recorrido en el trasmundo. La galería se presenta como un macabro espectáculo. Adornada con cuerpos vivos de nobles colgados en las paredes como retratos, «dichas figuras son originales que dramatizan a cada rey de manera mucho más verídica que cualquier pose convencional». ${ }^{102}$ Ahora bien, la posesión de una galería por parte de Lucifer supone, según Crosby, ${ }^{103}$ tanto una parodia de «las de los palacios de reyes y nobles» como una burla del rey como «coleccionista que aprecia y valoriza personas de reputación tan mala».

Partiendo del presupuesto que en el reinado de Felipe IV el coleccionismo de pintura constituía una parte significativa de la costumbre artística de la Corte madrileña,

\footnotetext{
${ }^{95}$ Quevedo, F., Sueños y discursos, ob. cit., pp. 177 y 1240.

${ }^{96}$ García SANTo-Tomás, E., Modernidad bajo sospecha..., ob. cit., p. 153.

${ }^{97}$ Salas Barbadillo, A. J., «El curioso y sabio...», ob. cit., p. 25.

${ }^{98}$ Maravall, J. A, La literatura ..., ob. cit., p. 746.

${ }^{99}$ Quevedo, F., Sueños y discursos, ob. cit., I, pp. 11 y 1321.

100 SAlas BARBADillo, A. J., «El curioso y sabio...», ob. cit., p. 11.

${ }^{101}$ Quevedo, F., Sueños y discursos, ob. cit., I, p. 188.

102 Quevedo, F., Sueños y discursos, ob. cit., I, p. 1305.

${ }^{103}$ Quevedo, F., Sueños y discursos, ob. cit., I, pp. 1305 y 1308.
} 
en un trabajo anterior ${ }^{104}$ también sugerimos la posibilidad de que detrás del anfitrión de la galería salasiana se hallase Felipe IV, que comparte la pasión artística con Alejandro. Asimismo, estudiamos cómo su colección de retratos podría corresponderse con la del Alcázar o con la de cualquiera de la alta nobleza del XVII que hiciese un uso aparatoso del coleccionismo. Al vincular estas hipótesis con las relaciones aquí establecidas entre Salas y Quevedo, tampoco es descartable que Salas parodiase tanto la colección de los nobles, o del rey mismo, como sus dueños coleccionistas, y nos referimos sobre todo al monarca Felipe IV, que custodia esas pinturas de personajes viciosos y ostentosos en sus «venerados retretes». ${ }^{105} \mathrm{Sin}$ embargo, estos aposentos privados y secretos (véase Aut: «retrete») de la casa del curioso Alejandro guardaban los retratos reservados a unos pocos elegidos y que bien podrían relacionarse con el aposento curioso de Lucifer: «porque tengáis que contar en el otro mundo, veáis su camarín» (I1208-1209). ${ }^{106}$ Tanto por su aseado como por ser una sala pequeña llena de galas utilizada por las mujeres, Quevedo lo presenta afeminado. Este afeminamiento del diablo, como la pasión por el lujo y el gasto suntuario que también se han visto en el «pulido limpión» de la segunda narración de Salas, representan las preocupaciones y los problemas de la nobleza de la época. Ya que estas manías manifestaban un desbarajuste de las clases sociales, se advertía, claro está, una amenaza para la seguridad estamental. ${ }^{107}$ En definitiva, el cuadro político-social que se deduce es el de un reinado que, pese a comenzar con grandes esperanzas de renovación en sus dos primeras décadas, representadas en la voracidad del glotón «Panza dichosa», quedó marcado por su desnutrición política y social debida a los engaños, fragilidades y apariencias que en realidad se hallaban detrás de una Panza/Corte «malvada o infernal», ${ }^{108}$ la que acabará con el coloso decaído y castigado del primer cuento, según el enclave político representado por el castigo de Ticio.

A pesar de todo, si bien se ha reconocido que detrás de «Panza dichosa» se escondían aquellos nuevos despreocupados madrileños, no descartamos que, en un plan más detallado, el monarca fuese el blanco de la crítica. Otra vez nos sirve de guía Quevedo. Si, por un lado, el poema «Nació Viernes de Passión» (M889-908) ${ }^{109}$ expresa las esperanzas que el país tenía a la subida al trono de Felipe IV; por el otro, la imagen diminuta que se le atribuye - «desempeña España / solamente con un quarto» - hace

${ }_{104}$ Coppola, L., «La galería artística como proyecto marco de El curioso y sabio Alejandro, fiscal y juez de vidas ajenas (1634): Salas Barbadillo en el Palacio del Rey Felipe IV», JANUS: estudios sobre el Siglo de Oro, 9 (2020), pp. 191-220." 191-220.

${ }^{105}$ Salas Barbadillo, A. J., «El curioso y sabio...», ob. cit., p. 2.

${ }^{106}$ Quevedo, F., Sueños y discursos, ob. cit., I, p. 189.

${ }^{107}$ GonZÁLEZ CAÑAL, R., «El lujo y la ociosidad...», ob. cit., pp. 93-95.

${ }^{108}$ SALAS BARBADILLO, A. J., «El curioso y sabio...», ob. cit., p. 5.

${ }^{109}$ Quevedo, F., Sueños y discursos, ob. cit., I, pp. 238-239. 
de sátira. ${ }^{110}$ Volviendo nuevamente a los detalles fisiognómicos, Crosby ${ }^{111}$ destaca la presentación del rey Alejandro Magno como «menudo de facciones» (v. 95) $)^{112}$ en el retrato satírico que Quevedo le dedica en el romance «Visita de Alejandro a Diógenes Cínico». ${ }^{113}$ Es más, se le calificó de «glotón del orbe» (v. 33), «gomia del mundo» (v. 51), «serenísima tarasca» (v. 52), «mocito / a manera del hampa» (vv. 93-94) y «muy gótico de espaldas» (v. 96). Las conquistas del «hidrópico monarca» (v. 30) Alejandro, insaciable como «Panza dichosa», son de «aquel que glotón del orbe, / engulle por su garganta / imperios como granuja / y reinos como migajas» (vv. 33-36) que bien podría ser la fuente del voraz «malvado varón» pintado por Salas en el cuento de abertura de su colección de ostentosos.

Para los fines de nuestro argumento, si en otro momento hemos considerado, según la unión de la disposición política con la formación sabia, a Alejandro Magno como modelo del Alejandro salasiano detrás del cual se escondería Felipe IV, tampoco es posible excluir que el autor buscase asimismo representar la faceta más oscura y muy bien escondida del soberano. Si bien en unas ocasiones Alejandro/Felipe IV aparece como figura ejemplar, en otras, en cambio, predomina la parodia y la mofa, como es el caso de los Sueños o del romance de Quevedo. Esta última actitud representaría, claro está, «una crisis de la ejemplaridad personificativa del Renacimiento». ${ }^{114}$ Tanto la temática seria, por un lado, como la burla, por el otro, indican una procedencia parecida entre Quevedo y Salas. Contrariamente al aspecto ideal del monarca, Salas, en este último caso, presentaría el lado infrarreal de Alejandro y, por lo tanto, de Felipe IV y su Corte. En este mismo sentido, la obra manifiesta la clásica paradoja barroca: Madrid es una ciudad que reúne abundancia y miseria, verdad y ficciones; lo que, en suma, se esconde detrás de los vicios como la Discordia, hija de la envidia, que «se fue a los Palacios y Cortes, donde es Lugarteniente de los diablos» (M362) $)^{115}$ y donde se imitan los excesos palaciegos que se representan de manera caricaturesca en El curioso y sabio Alejandro.

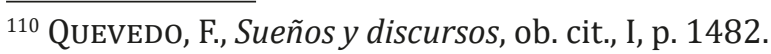

${ }^{111}$ QueVEDo, F., Sueños y discursos, ob. cit., I, p. 1504.

112 «Al que era menudo de facciones se le tenía por "pessimus, viciosus, deceptor, ebriosus"» (Secretum, VIII, 169).

${ }^{113}$ Quevedo, F., Obras completas, y I: Poesía original, J. M. Blecua (ed.), Barcelona, Planeta, 1968, núm. 745. Para este romance se recomienda MúÑoz CoRTÉs, M., «Sobre el estilo de Quevedo (Análisis del Romance Visita de Alejandro a Diógenes Cínico)», Anales de la Universidad de Murcia. Filosofía y Letras, 16, 3-4 (19571958), pp. 138-164.
}

${ }^{114}$ MúÑoz CoRTÉs, M., «Sobre el estilo...», ob. cit., p. 163.

${ }^{115}$ Quevedo, F., Sueños y discursos, ob. cit., I, p. 225. 
En conclusión, los seis relatos de Alejandro subrayan esa tensión entre «anhelo ideal y realidad degradada» que Rey Hazas ${ }^{116}$ destaca en la obra conjunta de Salas. Sin embargo, mientras en la mayoría de la producción se hace constar una sociedad imperfecta - donde el engaño y falsedad son la carta de presentación de personajes absurdos: pícaros, aprovechados, moriscos, viciosos, etc., que apenas se critican y censuran social y éticamente - y otra ideal - la sociedad de modelos tradicionales, nobles y de privilegios del pasado, manteniendo un mentalidad conservadora de un Quevedo que coteja la decadencia, la falaz y los vicios de la sociedad barroca española eximida de un pensamiento renovador - , con El curioso y sabio Alejandro notamos una más evidente ideología reformadora alcanzada con las digresiones morales con las que se cierra cada biografía. En el caso del primer cuento, Salas espera que un rayo, uno de los atributos de Júpiter - como el águila, la que nos llevaría al castigo de Ticio-, cayese para liberar al ser humano del desenfreno de esos gigantones que se rebelan a Zeus: «Roguemos, pues, al cielo, que nos envíe un rayo de su sagrada y liberalísima piedad, para que con su luz nos desatemos de las tinieblas de un vicio tan irracional, tan torpe y tan ciego». ${ }^{117}$ Por consiguiente, los colosos que se acaban de presentar valen de ejemplo moralizante para todos los que se enfrentaban al poder instituido y actualmente podrido: «sirva esto de algún desengaño, para que enfrenemos nuestros insaciables apetitos, [...] frenéticos deseos, y [...] bárbaras sensualidades». ${ }^{118}$ Como cierra el autor, ${ }^{119}$ para llegar a ser «varón casto» hay que inclinarse a la templanza, virtud que «corrige y templa todas las inobediencias y libertades de la glotona gula y de la lujuria torpe», ${ }^{120} \mathrm{y}$ «entrar primero por la puerta estrecha y cerrada de la abstinencia».

\section{BiblografíA}

Alvar EzQuerra, A., El nacimiento de una capital europea: Madrid entre 1561 y 1606, Madrid, Turner, 1989.

Álvarez-Ossorio Alvariño, A., «Rango y apariencia. El decoro y la quiebra de la distinción en Castilla (ss. XVI-XVIII)», Revista de historia moderna, 5, 17 (19981999), pp. 263-278.

Bergson, H., La risa, Barcelona, Plaza y Janés, 1956.

\footnotetext{
${ }^{116}$ Rey HaZas, A., Picaresca femenina..., ob. cit., p. 26.

${ }^{117}$ Salas Barbadillo, A. J., «El curioso y sabio...», ob. cit., p. 7.

118 Salas Barbadillo, A. J., «El curioso y sabio...», ob. cit., p. 6.

119 Salas Barbadillo, A. J., «El curioso y sabio...», ob. cit., p. 6.

${ }^{120}$ Aspecto también requerido en las artes visuales, como refiere en la «Epístola decimocuarta, en la que se mofa de la pintura de un pintor que solía alegrarse con el vino», donde «esto de pintar al temple será imposible en V.m porque quien dessea ser siempre fuego vinoso [...] no admitirá la templança» (SALAS Barbadillo, A. J., Don Diego de noche, Madrid, Viuda de Cosme Delgado, 1623, 35v).
} 
Bravo, M. D., «Los entremeses cervantinos, valores sociales y risa crítica: El retablo de las maravillas», en L. Von der Walde y S. González García (eds.), Dramaturgía española y novohispana (siglos XVI y XVII), Itzapalapa, México Universidad Autónoma Metropolitana, 1993, pp. 141-148.

Buj Bu, A., «La plaga de la langosta. Permanencia de un riesgo biológico milenario», Scripta Nova. Revista electrónica de Geografía y Ciencias Sociales, XII, 270 (2008). Disponible en: http:/ /www.ub.es/geocrit/sn/sn-270/sn-270-106.htm.

CAstro, A., "Como veo ahora el Quijote», estudio introductorio a la edición de El ingenioso don Quijote de la Mancha, Madrid, Magisterio Español, 1971.

Close, J. A., Cervantes y la mentalidad cómica de su tiempo, Alcalá de Henares, Biblioteca de Estudios Cervantinos, 2007.

Clymer, C., The representation of culture in Golden Age Madrid: between attraction and repugnance, Nottingham, University of Nottingham (Tesis doctoral) (2014).

Coppola, L., «La galería artística como proyecto marco de El curioso y sabio Alejandro, fiscal y juez de vidas ajenas (1634): Salas Barbadillo en el Palacio del Rey Felipe IV», JANUS: estudios sobre el Siglo de Oro, 9 (2020), pp. 191-220." 191-220.

Coppola, L., «Salas Barbadillo y el quehacer grotesco: “Las líneas de este pincel y los renglones de esta pluma" en El curioso y sabio Alejandro, juez y fiscal de vidas ajenas (1634)" ", en M. Albert, V. Aranda Arribas, L. Coppola (eds.), La narrativa de Alonso Jerónimo de Salas Barbadillo, Berlín, Peter Lang (Bonner Romanistische Arbeiten, 121), 2020, pp. 203-223.

Chevalier, M., «Cuestiones de aseo Luis Zapata, Lucas García Dantisco, Alonso Quijano», Incipit, 11 (1991), pp. 153-160.

Durán Guerra, L., «Don Quijote como universal fantástico», Anales Cervantinos, 50 (2018), pp. 75-103.

Freud, S., «El humor», en Obras Completas, Vol. XXI, Buenos Aires, Amorrortu, 1991. , «El chiste y su relación con lo inconsciente», en Obras Completas, Vol. VIII, Buenos Aires, Amorrortu, 1995.

García SAnto-Tomás, E., Espacio urbano y creación literaria en el Madrid de Felipe IV, Madrid, Universidad de Navarra-Iberoamericana-Vervuert, 2004.

, E., Modernidad bajo sospecha. Salas Barbadillo y la cultura material del siglo XVII, Madrid, CSIC, 2008.

GonZÁlez CAÑAL, R., «El lujo y la ociosidad durante la privanza de Olivares: Bartolomé Jiménez Patón y la polémica sobre el guardainfante y las guedejas», Criticón, 53 (1991), pp. 71-96.

Hernández GonzÁlez, M. ${ }^{a}$ B., «El humor, la ironía y el cómico: códigos transgresores de lenguajes e ideologías», Signa: revista de la Asociación Española de Semiótica, 8 (1999), pp. 218-233.

Maestro, Jesús G., «Cervantes y el entremés, poética de una comicidad crítica», en F. B. Pedraza Jiménez y R. González Cañal, Con los pies en la tierra. Don Quijote en 
su marco geográfico e histórico, 2 vols., I, Cuenca, Universidad de Castilla / La Mancha, 2008, pp. 525-536.

Maravall, J. A., La literatura picaresca desde la historia social, Madrid, Taurus, 1986. , La cultura del Barroco, Barcelona, Planeta, 2012.

Martínez-Góngora, M., El hombre atemperado: Autocontrol, disciplina y masculinidad en textos españoles de la temprana modernidad, Nueva York, Peter Lang, 2005.

Múñoz Cortés, M., «Sobre el estilo de Quevedo (Análisis del Romance Visita de Alejandro a Diógenes Cínico)», Anales de la Universidad de Murcia. Filosofía y Letras, 16, 3-4 (1957-1958), pp. 138-164.

Piqueras Flores, M., Alonso Jerónimo de Salas Barbadillo y la conformación de las colecciones de metaficciones en el Madrid cortesano, Tesis doctoral defendida en la Universidad Autónoma de Madrid, Facultad de Filosofía y Letras, Departamento de Filología Española, 2016.

Quevedo, F. Obras completas, y I: Poesía original, J. M. Blecua (ed.), Barcelona, Planeta, 1968.

, Sueños y discursos, 2 vols., J. O. Crosby (ed.), Madrid, Castalia, 1993.

Rey HazAs, A., Picaresca femenina (La hija de Celestina. La niña de los embustes, Teresa de Manzanares), Barcelona, Plaza y Janés, 1986.

Salas Barbadillo, A. J., Don Diego de noche, Madrid, Viuda de Cosme Delgado, 1623.

, Coronas del Parnaso y platos de las Musas, Madrid, Imprenta del Reino, 1635.

, «El curioso y sabio Alejandro, fiscal y juez de vidas ajenas», en E. de Ochoa (ed.), Tesoro de novelistas españoles antiguos y modernos, t. II, París, Fain y Thunot, 1847.

El caballero puntual, E. López Martínez (ed.), Madrid, Real Academia Española/ Centro para la Edición de Clásicos Españoles, 2016. Disponible en: https:// revistas.unav.edu/index.php/rilce/article/view/37744

VITSE, M., «Salas Barbadillo y Góngora: burla e ideario de la Castilla de Felipe III», Criticón, 80 (1980), pp. 5-142.

ZAFrA, R., «El prudente Tiziano y su emblema de la prudencia», Potestas. Revista del Grupo Europeo de Investigación Histórica, 3 (2010), pp. 123-146. 